Article

\title{
Proposal for a Safety Qualification Program for Vehicle-Integrated PV Modules
}

\author{
Jochen Markert $^{1, *}$, Christoph Kutter ${ }^{1, *}$, Bonna Newman ${ }^{2}$, Paul Gebhardt ${ }^{1} \mathbb{D}$ and Martin Heinrich ${ }^{1}$ \\ 1 Fraunhofer Institute for Solar Energy Systems ISE, Heidenhofstrasse 2, 79110 Freiburg, Germany; \\ paul.gebhardt@ise.fraunhofer.de (P.G.); martin.heinrich@ise.fraunhofer.de (M.H.) \\ 2 TNO Energy Transition, Solar Energy, 1755 ZG Petten, The Netherlands; bonna.newman@tno.nl \\ * Correspondence: jochen.markert@ise.fraunhofer.de (J.M.); christoph.kutter@ise.fraunhofer.de (C.K.); \\ Tel.: +49-761-4588-5879 (J.M.); +49-761-4588-2196 (C.K.)
}

Citation: Markert, J.; Kutter, C.; Newman, B.; Gebhardt, P.; Heinrich, M. Proposal for a Safety Qualification Program for Vehicle-Integrated PV Modules. Sustainability 2021, 13, 13341. https://doi.org/10.3390/ su132313341

Academic Editors: Miguel Centeno Brito and Kenji Araki

Received: 5 November 2021

Accepted: 27 November 2021

Published: 2 December 2021

Publisher's Note: MDPI stays neutral with regard to jurisdictional claims in published maps and institutional affiliations.

\begin{abstract}
We propose a safety qualification program for vehicle-integrated photovoltaic (VIPV) modules, which could serve as a simplification, thereby accelerating the homologation process of new vehicle designs. The basis is the current photovoltaic (PV) module safety qualification, as defined in IEC 61730:2016, which is compared to automotive norms and regulations because additional safety requirements have to be considered for PV modules used in this application. Therefore, testing based on regulations that concern electrical and electronic equipment in vehicles (ISO 16750), rupture safety of glass and laminated glass in vehicles (ECE R43), and pedestrian safety (ECE R127) are assessed and compared in terms of severity. Additionally, optional testing concerning the long-term stability of VIPV modules is recommended, as a guideline for vehicle manufacturers. If assessed to be necessary, the qualification program of IEC 61730 is complemented by the respective tests to finally present a conclusive safety qualification program for VIPV modules in new vehicle designs.
\end{abstract}

Keywords: VIPV modules; safety qualification; homologation

\section{Towards Homologation of Vehicle-Integrated Photovoltaics}

One market that has drawn a lot of attention lately, regarding the topic of integrated photovoltaics (PV), is the automotive industry [1-5]. This is especially attributed to the increase in electric vehicles that offer a direct utilization of the generated solar power, resulting in potential benefits for customers as well as power grid operators (i.e., reduced number of charging stops, reduced grid utilization). Additionally, the ongoing price drop on the PV market [6] is reducing the focus on an optimal orientation of the modules towards the sun to achieve highest yield and lowest payback time. Vehicle-integrated photovoltaics (VIPV) can generate significant solar ranges [2], and VIPV products are already commercially available. For example, the Hyundai Sonata [7] or the solar charging system developed by Toyota [8]. Both use a VIPV module in the roof. Figure 1 (left) shows an example of a modern solar roof using shingled crystalline Si solar cell technology [9]. The evolution of concepts in this field is ongoing, and solar electric vehicles (SEVs) featuring solar cells in the whole autobody are currently under development. The passenger vehicle Sion by Sono Motors GmbH [10] uses an autobody, in which PV is integrated into almost all external body surfaces, and the Lightyear One with a solar roof, bonnet, and boot, are further examples of the current high interest in the vehicle industry [11]. Multiple other projects and products use VIPV modules e.g., in commercial trucks, where lightweight VIPV modules are integrated into the rooftops of box bodies [1], as shown in Figure 1 (right). 

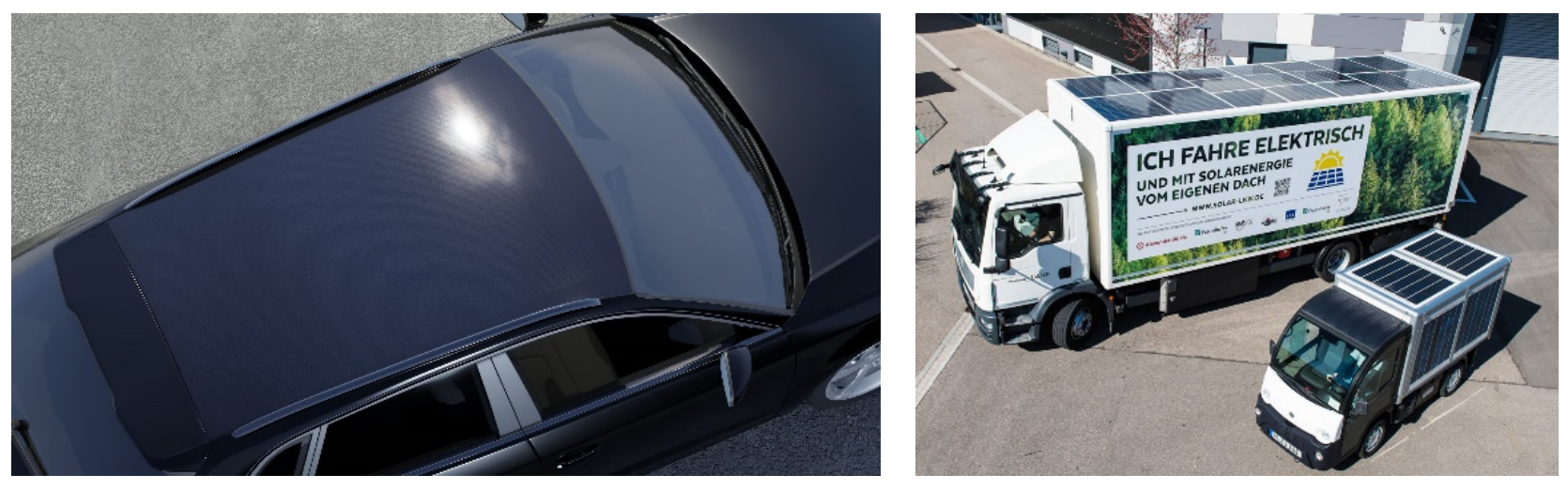

Figure 1. Solar roof design for cars built at Fraunhofer ISE (left), and concept truck equipped with VIPV modules on the roof (right).

New designs of planar conventional PV modules must be certified according to the safety requirements defined in IEC 61730-2:2016 [12,13] and IEC 61215-2:2021 [14,15], prior to market release. On the automotive side, vehicle components have to fulfill requirements according to a number of standards to ensure safety during vehicle operation. In the case of VIPV modules, each of the required tests on both sides must be passed independently to verify safe operation on the module level as well as on the vehicle level. After ensuring comprehensive component safety by passing all required tests from the mentioned standards, the new design can be applied to the homologation process guided by the road authority of the respective country. The requirements for a vehicle or component to be homologated for roadworthiness are defined in part (13) of directive 2009/661/EC [16]. Since the changes applied to the vehicle in the case of VIPV modules are limited to "the vehicle exterior and accessories", the respective IEC standards for PV and ISO as well as the ECE standards that apply for these exterior elements are relevant. In Table 1 we collected the relevant standards, which may be applicable for VIPV modules.

In this article, we propose a safety qualification program for VIPV modules for the use in vehicle classes $M$ (vehicles having at least four wheels and used for the carriage of passengers) and $\mathrm{N}$ (vehicles having at least four wheels and used for the carriage of goods), according to EU decree 2018/858 [17], which combines all necessary testing requirements from standards on the PV and automotive sides. The testing structure from IEC 61730-2:2016 [13] for newly developed PV modules will serve as the basis, since it tests specifically for the safety of PV modules and will be customised by the addition, removal, and modification of tests. To this end, requirements from IEC 61730:2016 and IEC 61215:2021 are compared to specifically select automotive standards, as shown in Table 1. Further requirements for these special devices will be laid out to finally present a conclusive safety qualification program for VIPV modules, which could simplify and, hence, accelerate the type approval process for new vehicle designs.

Similar to the safety qualification for PV modules defined in IEC 61730:2016 [12,13], the presented proposal covers VIPV devices including the cables and connectors to the vehicle electronics. We will refrain from a detailed study of requirements regarding the complete vehicle as, e.g., is present in ECE-R10 [20]. However, requirements concerning failure modes in the electronic system that may occur, for example, during a crash event, as described in ECE-R95 [22], must be respected and have to be examined separately. Furthermore, we disregard quality characteristics on the material level (e.g., RoHS [26]) and tests concerning module quality and performance are only added if concerned with environmental stability and safety. 
Table 1. Automotive standards and respective scopes used throughout this article.

\begin{tabular}{|c|c|}
\hline Standard & Scope \\
\hline ISO $16750(-1,-2,-3,-4,-5)[18]$ & $\begin{array}{l}\text { Road vehicles_Environmental conditions and } \\
\text { testing for electrical and electronic equipment: } \\
\text { Part 1: General } \\
\text { Part 2: Electrical loads } \\
\text { Part 3: Mechanical loads } \\
\text { Part 4: Climatic loads } \\
\text { Part 5: Chemical loads }\end{array}$ \\
\hline ISO 20653 [19] & $\begin{array}{l}\text { Road vehicles-Degrees of protection (IP } \\
\text { code) - Protection of electrical equipment against } \\
\text { foreign objects, water, and access }\end{array}$ \\
\hline ECE-R10 [20] & $\begin{array}{l}\text { Uniform provisions concerning the approval of } \\
\text { vehicles with regard to electromagnetic compatibility }\end{array}$ \\
\hline ECE-R43 [21] & $\begin{array}{l}\text { Uniform provisions concerning the approval of } \\
\text { safety glazing materials and their installation on } \\
\text { vehicles }\end{array}$ \\
\hline ECE-R95 [22] & $\begin{array}{l}\text { Uniform provisions concerning the approval of } \\
\text { vehicles with regard to the protection of the } \\
\text { occupants in the event of a lateral collision }\end{array}$ \\
\hline ECE-R100 [23] & $\begin{array}{l}\text { Uniform provisions concerning the approval of } \\
\text { vehicles with regard to specific requirements for the } \\
\text { electric power train }\end{array}$ \\
\hline ECE-R118 [24] & $\begin{array}{l}\text { Uniform technical prescriptions concerning the } \\
\text { burning behavior of materials used in the interior } \\
\text { construction of certain categories of motor vehicles }\end{array}$ \\
\hline ECE-R127 [25] & $\begin{array}{l}\text { Uniform provisions concerning the approval of } \\
\text { motor vehicles with regard to their pedestrian safety } \\
\text { performance }\end{array}$ \\
\hline
\end{tabular}

\section{Review of Normative References and Regulations}

Integrating PV modules into vehicle components implicates a comprehensive safety assessment prior to the homologation process. Hereby, the added PV functionality must not comprise the roadworthiness of the vehicle itself, as stated in Directive 2009/661/EC: "It is appropriate that vehicles be designed, constructed and assembled so as to minimise the risk of injury to their occupants and other road users". The relevant key issues must concern: general testing, electrical loads, fire hazards, mechanical loads, environmental stresses and chemical stability of the devices, as discussed in IEC 61730 and ISO 16750. Furthermore, the safety of VIPV modules may need to also be ensured during operation in a damaged state or after a crash event; these are topics that have not been of interest for conventional PV modules in the past.

\subsection{Comparison of Standards}

IEC 61730 provides unified guidelines for the safety qualification of conventional photovoltaic modules. ISO 16750 describes potential environmental stresses as well as specific tests and requirements for electric and electronic components for vehicles for specific mounting locations in and on vehicles. Since similar tests, but some with different specifications, are described in both standards, a comparative assessment and a subsequent selection of the most stringent testing was applied.

Testing Categories and Pass Criteria

The two standards can be classified into the five following sub-sections:

- General

- Electrical loads

- Fire hazards 
- Mechanical loads

- Environmental/climatic loads

- Chemical loads

The requirements in every sub-section of ISO 16750 are defined by so-called "code letters", which account for a specific set of parameters in the respective test section applicable to the device under test (DUT), which are determined by the mounting location, the max. operation temperature, the vehicle class, and/or the performance class [18]. In case of VIPV modules, the agreements with the specified parameters have to be checked carefully and, if necessary, a new code letter " $Z$ " with adapted test parameters can be applied when the supplier and/or vehicle manufacturer determine that the conditions or tests defined in the ISO 16750 series are not suitable to achieve desired product quality/reliability objectives and/or are not practical [18]. Pass criteria as they are defined in ISO 16750-1 are associated with specific functional status classifications as, e.g., class A: "All functions of the device/system perform as designed during and after the test" or class E: "One or more functions of a device/system do not perform as designed during and after the test and cannot be returned to proper operation without repairing or replacing the device/system" [18]. Classifying a VIPV module according to those functionality classes is, however, not assumed to be sufficient; consequently, the pass criteria from the PV side, as defined in IEC 61730:2016 [12,13], are used in the further course to ensure safe operation of the VIPV modules in terms of electrical functionality and mechanical design. Regarding module quality, which is a non-safety-related key issue for the market acceptance of VIPV systems, we suggest to comply with the $5 \%$ power loss criteria specified in IEC 61215 for terrestrial photovoltaic modules [14,15].

\subsection{General Inspection}

Certification of IEC 61730-2 starts with general inspection tests aiming at the overall functionality and manufacturing quality of the module: visual inspection (MST 01), performance measurement at standard conditions (STC) (MST 02), maximum power determination (MST 03), insulation thickness (MST 04), durability of markings (MST 05), sharp edge (MST 06), and bypass diode functionality (MST 07) [13]. Pass criteria after the respective aging tests in IEC 61730-2 are, in general, defined by passing MST 01 (visual inspection) and the insulation tests MST 16 and MST 17, as mentioned in the following Section 2.3, respectively. Tests concerning a general inspection of devices are not defined in ISO 16750.

\subsection{Electrical Protection/Electrical Loads}

In general, $\mathrm{PV}$ and, hence, VIPV modules must have an adequate protection against electric shock, which is guaranteed by compliance with requirements of class II according to IEC 61140 [27] or, correspondingly, class A as defined in IEC 61730-1 [12]. Another major aspect when it comes to the safety qualification of newly designed modules is the conformity with the requirements dependent on the maximum system voltage, according to IEC 61730-1 [12]. Accordingly, all modules must feature appropriate insulation thickness and creepage distance specifications (acc. to Table 3 in IEC 617301 [12]). Especially, the application of new materials in PV module manufacturing poses additional effort, because material parameters such as the comparative tracking index (CTI) and the relative temperature index (RTI) have to be determined. CTI is a numerical index value related to the maximum voltage, which a material can withstand without a permanent electrically conductive carbon path track when evaluated under specified test conditions, as defined in IEC 60112 [28]. The RTI of an insulating material or system is a value obtained from the time that corresponds to the known temperature index of a reference material or system, when both are subjected to the same aging and diagnostic procedures in a comparative test, according to IEC 60050-212 [29]. For a simplification, and to thereby accelerate the homologation process, device manufactures may use already established compounds in PV manufacturing with well-known material parameters. 
Furthermore, both standards cover the topic of electrical loads according to their respective requirements, which in some parts appear conflicting. The DUTs in ISO 16750-2 mainly refer to consumer loads, while a PV module represents a generator. ISO 16750-2 defines the requirements corresponding to the maximum supply voltage of devices with $12 \mathrm{~V}$ and $24 \mathrm{~V}$, respectively. A new code letter " $\mathrm{Z}$ " can be introduced to reflect the supplied voltages for one respective PV system under operation. Tests from IEC 61730-2 in this section comprise: accessibility test (MST 11), cut susceptibility test (MST 12), continuity test for equipotential bonding (MST 13), impulse voltage test (MST 14), insulation test (MST 16), and wet leakage current test (MST 17) [13]. As mentioned before, the insulation tests MST 16 and MST 17 serve as pass criteria after most of the aging tests throughout IEC 61730-2.

The section "4.3 Overvoltage" of ISO 16750-2 ensures safe operation when the generator regulator fails and the output voltage of the generator rises above normal values [18]. That is, however, an unrealistic scenario in the case of PV module operation. The impulse voltage test in IEC 61730-2 (MST 14), which defines modules to withstand over-voltages of atmospheric origin [13] (e.g., lightning), seems to be an equivalent test for VIPV modules. Since VIPV modules are classified as class II according to IEC 61140, the insulation resistance measurement MST 16 (IEC 61730-2) is assumed to adequately reproduce realistic conditions, and no further criteria concerning insulation issues of ISO 16750-2 must be considered. Therefore, a preceding damp-heat cycle, which is demanded in ISO 16750-2 [18], will be disregarded, since this environmental stress is applied with more intensive loads during Sequence D in IEC 61730-2 [13]. A PV module represents a generator and, hence, tests from ISO 16750-2 concerning direct current supply (4.2), slow decrease and increase in supply voltage (4.5), discontinuities in supply voltage (4.6), and ground reference and supply offset (4.8) [18], are not applicable for qualification. Section 4.11 (withstand voltage) is only mandatory for applications including inductive elements, which also does not account for PV modules. Moreover, an open circuit test (4.9), as well as a test concerning short circuit protection (4.10), is not regarded to be necessary, because no additional risks are expected when operating in these modifications. Tests that are not directly connected to the safety qualification of VIPV modules, but could become important in the final testing on the vehicle side, are superimposed alternating voltage (4.4) and those that check the electromagnetic compatibility (EMC). One additional test mentioned in this section (4.7 reversed voltage) is, according to ISO 16750-2, not applicable to generators. Due to safety considerations, however, reverse operation of the PV devices must be considered and is discussed in the following section, "fire hazards".

Regulation ECE-R100 defines the approval of vehicles due to their requirements concerning the electrical drive and mentions advanced safety requirements. One example is section "5.1.1.3 Connectors, $(\mathrm{d})$ ", where it is defined that the voltage of active parts has to be equal or below $60 \mathrm{~V} \mathrm{DC}$ within one second after the separation of connectors, which could be the case after a crash event. One approach could be to limit the overall system voltage to a maximum of $60 \mathrm{~V} \mathrm{DC}$ and thereby avoid conflicts with the safety requirements of a "high voltage" system defined in this regulation. This would also be accompanied by a reduction of the prescribed insulation thicknesses, as mentioned earlier.

\subsection{Fire Hazards}

Protection against fire hazards is crucial and especially important during and after crash events. Defined tests in IEC 61730-2 comprise a temperature test (MST 21), a hot-spot endurance test (MST 22), an ignitability test (MST 24), a bypass diode thermal test (MST 25), and a reverse current overload test (MST 26) [13]. The definition of the respective test current in MST 26 may be adapted by the safety design of the module concept. An explicit fire test (MST 23), as mentioned, refers directly to building standards for BIPV applications. Apart from the ignitability test, a flammability class of minimum V1 according to IEC 60695-11-10 [30] is demanded for materials that are used on the exterior (not thin layers) of PV modules in IEC 61730-1 [13]. On the automotive side, a separate legal act, ECE-R118 deals with this issue. Those tests are, however, solely applicable to materials used in 
the passenger compartment, the engine compartment, and in separate boiler rooms [24]. Moreover, a fire test defined in ECE-R43 is only applicable to materials used in the passenger compartment. If it is guaranteed that no flammable splinters can penetrate into the interior of the vehicle after module breakage, which can be ensured by compliance with the rupture and splinter resistance in ECE-R43, no further demonstration of fire resistance beyond the requirements of the specifications in IEC 61730-2, is proposed.

Special attention shall be paid to hot-spot formation in VIPV modules and the development of an appropriate certification test sequence. Previous observations suggest that vibrational loads, as they are expected during VIPV operation, increase the probability of crack formation and/or propagation in solar cells. Consequently, the risk of hot-spot formation, which might exceed the worst-case scenario examined throughout the hot-spot test according to IEC 61730-2:2016, is assumed to be significantly increased. However, the topic has to be investigated in more detail, before a conclusive assessment can be given. For a first approximation to the topic, a vibrational test, according to ISO 16750-3 prior to the hot-spot test in the certification sequence, is proposed.

\subsection{Mechanical Loads}

\subsubsection{Mechanical Robustness and Vibrational Loads}

Tests concerning mechanical loads in IEC 61730-2 comprise a cut susceptibility test (MST 12), a module breakage test (MST 32), a screw connection test (MST 33), a static mechanical load test (MST 34), a peel test (MST 35), a material creep test (MST 37), and a robustness of terminations test (MST 38) [13]. The static mechanical load test (MST 34) in its original shape is assumed to not appropriately simulate mechanical loads that arise during vehicle operation. The test can, however, serve as a basis with individual alignments due to the mounting type and location, e.g., a VIPV bonnet module, which is exposed to mechanical stresses originating from air streams at high velocities. It might also be necessary to ensure the static mechanical load stability of a roof-top module, when the vehicle rolls over in a crash event and remains in an upside-down position.

Also, it is mandatory to consider the supporting structure and the mounting specifications used in the vehicle, to reproduce mechanical conditions and restraints as realistically as possible. Additionally, loads in the form of vibrations originating from door slamming or rough road driving that were not of interest in conventional PV applications become crucial to state the stability and, consequently, the safety of VIPV modules. Therefore, we recommend to extend the mechanical load testing by the tests from ISO 16750-3 [18]. Dependent on the vehicle class ( $\mathrm{M}$ or $\mathrm{N}$ ) and the mounting location, different requirements have to be considered, which in the case of VIPV modules are confined to the section "Mounting on the exterior" and the corresponding code letters D, E, K, and L, according to ISO 16750-3 [18]. Under this directive, DUTs have to pass a vibrational test concerning sprung masses (test IV-passenger vehicles or test VII-commercial vehicles) and a mechanical shock test that simulates door slamming [18].

A test concerning the stability against free fall is also mentioned, but assessed to be not applicable for VIPV modules, since the breakage and splinter protection is tested elsewhere (ECE-R43), and a quality test after breakage is not demanded in the context of the here-presented proposal. In especially exposed mounting locations (e.g., front fender, side doors etc.), a test concerning the rupture safety due to gravel bombardment as indicated in ISO16750-3 can be reasonable to evaluate the mechanical stability of the module. Furthermore, long-term stability during vehicle operation can be ensured by such testing. The same accounts for a hail test, as defined in IEC 61215-2 (MQT 17). Since a damaged module will probably not be identified immediately in the case of VIPV, continuative mechanical testing after breakage could further increase the overall system safety.

A test called "Surface Strength/Scratch and Abrasion Resistance" in ISO 16750-3 is not specifically defined and not mandatory, but has to be agreed upon between manufacturer and customer [18]. For market acceptance, however, a specific definition of this section is recommended, so that the scratch resistance of modules for scenarios such as removal of 
snow loads, shopping cart collisions, or branches scratching over the surface when passing trees, is ensured. An experimental setup could be an enhancement of the cut susceptibility test for polymeric surfaces of PV modules (MST 12) in IEC 61730-2, where a small wagon pulls a blade with a defined load $(=8.9 \mathrm{~N})$ and velocity $(=150 \mathrm{~mm} / \mathrm{s})$ over the DUT [13], as indicated in Figure 2. This test could be modified by changing the blade shape and material (e.g., to a wooden stick) and adjusting the load, the pulling velocity, and the repetitions applied to the DUT, to thereby simulate different stress scenarios. In the interest of robust VIPV modules, we suggest to perform the test to all relevant external surfaces regardless of the kinds of materials used. In terms of market acceptance, the pass criteria could be reviewed and stringent, e.g., so that not only the insulation properties, but also visual damages, lead to failure of the test.

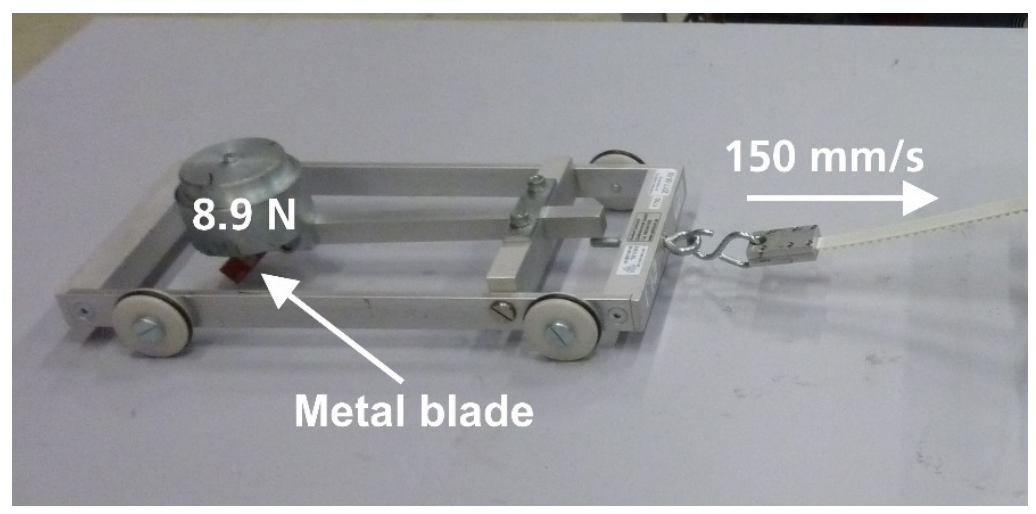

Figure 2. Setup at Fraunhofer ISE for the cut susceptibility test (MST 12), with a metal blade with an applied force of $8.9 \mathrm{~N}$ that is pulled over the DUT.

\subsubsection{Rupture Safety}

Additional testing, according to ECE-R43 (laminated safety glass [21]) and ECE-R127 (pedestrian safety [25]), is necessary to ensure comprehensive safety of the modules. In ECE-R43, dependent on the type and thickness of glass used in the module (tempered glass, laminated glass, or glass-polymer) or polymer glazing (rigid polymer or double glazing), the tests have to be selected according to the tables in Section 8.2.1.1— "Other than windshields" and 8.2.1.2 "Polymer glazing other than windshields" [21], respectively. One mechanical test, which is applicable in each case but with different drop heights and at different temperature preconditioning dependent on the material and thickness of the DUT, is the $227 \mathrm{~g}$ ball drop test. The rupture safety is ensured by passing the test, without penetration of the ball through the material and no breakage into sharp pieces. The phantom fall test defined in the ECE-R43 is discussed in comparison with tests from other standards in the section below. Furthermore, an abrasion test is mentioned, which is advised to be replaced by the formerly described test concerning scratch and abrasion resistance on a qualitative level. Tests concerning optical properties are not necessary, because no VIPV module will be installed in the field of vision of drivers. For laminated polymers, however, the brittleness and the adhesion also have to be determined with the cross cut test, as defined in A3/13 of ECE-R43 [21].

\subsubsection{Pedestrian Safety}

Another new requirement for VIPV modules that does not apply for conventional PV modules in field operation concerns pedestrian safety. Passing those requirements is crucial, because no type approval will be issued for vehicles when pedestrian safety is not ensured. Therefore, externally mounted VIPV modules have to pass tests with two different focus points: (a) legform to bumper test-DUTs mounted directly on the vehicle front which is up to now an unusual position for mounting a VIPV module, and (b) headform test-applicable to DUTs mounted in the hood-area and, currently, interesting 
for module mounting [25]. The latter test is, hence, especially important for VIPV modules in this mounting location and has to be passed with head injury criterion (HIC) values of $\leq 1000$ and $\leq 1700$ in the respective areas, as defined in the regulation [25]. The HIC is a dimensionless value and is calculated from the acceleration values determined throughout the headform test. Here, representative mounting and support, as will be used on the vehicle, is important for accurate results.

\subsubsection{Comparison of Three Different Impact Test Scenarios}

An example of how equivalent tests from different standards vary throughout their specifications is shown within Table 2. In each standard, a test including an impact of a different type that represented the maximum load in the respective standard applicable to VIPV modules was chosen: the module breakage test (MST 32) from IEC 61730-2 [13] is compared to the phantom fall test from ECE-R43 [21] and the adult headform test from ECE-R127 [25]. The calculated energy of the impactor is highest during the phantom fall test, as defined in ECE-R43. Due to the equivalent pass criteria, we assess that the module breakage test, according to IEC 61730-2, can be omitted without losing module safety, when the phantom fall test is applied to full modules instead of only material samples, as requested in ECE-R43 [21]. The headform test, according to ECE-R127, must be executed regardless in the case of bonnet modules, so that pedestrian safety is completely guaranteed.

Table 2. Comparison of test setups, sample specifications, impact energies, and requirements of three tests in different standards: (a) module breakage test (from IEC 61730-2 [13]); (b) phantom fall test (from ECE-R43 [21]); and (c) adult headform test (from ECE-R127 [25]).

\begin{tabular}{|c|c|c|c|}
\hline & $\begin{array}{c}\text { IEC 61730-2 } \\
\text { Module Breakage Test }\end{array}$ & $\begin{array}{c}\text { ECE-R43 } \\
\text { Phantom Fall Test }\end{array}$ & $\begin{array}{c}\text { ECE-R127 } \\
\text { Adult Headform Test }\end{array}$ \\
\hline Impactor Weight & $45 \mathrm{~kg}$ & $10 \mathrm{~kg}$ & $4.5 \mathrm{~kg}$ \\
\hline Test Setup & $\begin{array}{c}\text { Pendulum } \\
1 \geq 1525 \mathrm{~mm}\end{array}$ & Free fall & Free fall \\
\hline Test Specification & Drop height $=300 \mathrm{~mm}$ & $\begin{array}{c}\text { Drop height }=3 \mathrm{~m} \\
\text { (when head injury is expected) }\end{array}$ & Impact velocity $=9.7 \mathrm{~m} / \mathrm{s}$ \\
\hline $\begin{array}{c}\text { Sample } \\
\text { Specifications }\end{array}$ & PV module & $\begin{array}{c}\text { Material sample } \\
6 \text { plane samples: } 1100 \times 500 \\
\mathrm{~mm}^{2} \text { (glass) } 1170 \times 570 \mathrm{~mm}^{2} \\
(\text { Polymer }) \text { or complete unit }\end{array}$ & $\begin{array}{l}\text { Whole vehicle front (with } \\
\text { bonnet) }\end{array}$ \\
\hline Energy of Impact & $132 \mathrm{~J}$ & $294 \mathrm{~J}$ & $212 \mathrm{~J}$ \\
\hline \multirow[t]{2}{*}{ Pass Criteria } & \multirow{2}{*}{$\begin{array}{l}\text { No separation from mounting } \\
\text { structure or framing and no } \\
\text { breakage or no opening } \\
>\varnothing=76 \mathrm{~mm} \text { shall develop } \\
\text { and no particles }>65 \mathrm{~cm}^{2} \text { shall } \\
\text { be ejected from the sample. }\end{array}$} & $\begin{array}{c}\text { Rigid and Double Polymer } \\
\text { Glazing: } \\
\text { Sample shall not be } \\
\text { penetrated or break into } \\
\text { separated pieces; When head } \\
\text { injury is expected: HIC }<1000\end{array}$ & \multirow{2}{*}{$\begin{array}{l}\text { HIC recorded shall not exceed } \\
1000 \text { over two thirds of the } \\
\text { combined child and adult } \\
\text { headform test areas. } \\
\text { The HIC for the remaining } \\
\text { areas shall not exceed } 1700 \text { for } \\
\text { both headforms. }\end{array}$} \\
\hline & & $\begin{array}{c}\text { Glass: } \\
\text { Sample shall not be } \\
\text { penetrated or break into } \\
\text { separated pieces, breakage of } \\
\text { glass allowed }\end{array}$ & \\
\hline
\end{tabular}

\subsection{Climatic Loads}

Since PV modules are especially dedicated to outdoor operation, climatic testing has been essential from the beginning to ensure electrical system safety. For standard PV modules, this is approved by passing the module qualification, as defined in IEC 61730-2 [13]. Similar tests for electrical applications are also defined on the automotive side in ISO 16750-4, depending on the respective mounting location on the vehicle [18]. The installation site of 
VIPV modules will be standard on the exterior (body, frame, and/or doors), so that climatic testing corresponding to code letter D, according to Table 4 in ISO 16750-4 [18], applies. The recommended temperature range in which the tests are executed shall be changed from code letter $\mathrm{E}$, which applies to externally mounted parts (T-range $=-40{ }^{\circ} \mathrm{C}$ to $75^{\circ} \mathrm{C}$ ), to $\mathrm{G}$ (T-range $=-40{ }^{\circ} \mathrm{C}$ to $85^{\circ} \mathrm{C}$ ), to provide conformity to the requirements for PV modules defined in IEC 61730-2 [13]. However, a further extension of the temperature range to code letter I (max. $95^{\circ} \mathrm{C}$ ) may be used, if desired, for quality control by the manufacturer. Table 3 shows a compilation of the climatic tests of IEC 61730-2 on the left, which comprise temperature cycle (MST 51), humidity freeze (MST 52), damp heat (MST 53), UV preconditioning (MST 54), cold conditioning (MST 55), and dry hot conditioning (MST 56) [13]. For all of those, a comparable test with similar testing conditions is present in ISO 16750-4 (Table 3, right). Since the testing conditions of IEC 61730-2 are consistently harsher than in ISO 16750-4, the use of the general climatic tests from the PV standards is concluded to be sufficient to ensure the weatherability and, conclusively, proves electrical system safety in different climatic conditions more than equally.

Table 3. Comparison of climatic tests defined in IEC 61730-2:2016 and ISO 16750-4.

\begin{tabular}{|c|c|c|c|}
\hline \multicolumn{2}{|c|}{ IEC 61730-2 } & \multicolumn{2}{|c|}{ ISO 16750-4 } \\
\hline Tests & Conditions & Tests & Conditions \\
\hline \multirow{2}{*}{$\begin{array}{l}\text { MST } 51-\text { Temperature } \\
\text { Cycle-TC50 or TC200 }\end{array}$} & \multirow{2}{*}{$\begin{array}{l}-40-85^{\circ} \mathrm{C}, \max .100^{\circ} \mathrm{C} / \mathrm{h}, \\
\text { min. } 10 \text { min dwell time }\end{array}$} & 5.2 Temperature step test & $\begin{array}{c}5{ }^{\circ} \mathrm{C} \text { steps from } 20{ }^{\circ} \mathrm{C}->\mathrm{T}_{\min } \\
->\mathrm{T}_{\max } \\
\text { (acc. to code letter } \mathrm{G} \text { ) }\end{array}$ \\
\hline & & $\begin{array}{l}\text { 5.3.1 Temperature Cycling } \\
\text { (TC30) }\end{array}$ & $\begin{array}{l}150 \text { min at } T_{\min }+410 \mathrm{~min} \text { at } \\
\qquad \mathrm{T}_{\max } \\
\text { (acc. to code letter } \mathrm{G} \text { ) }\end{array}$ \\
\hline MST 52-Humidity Freeze & 10 cycles, $-40-85^{\circ} \mathrm{C}, 85 \% \mathrm{rH}$ & $\begin{array}{c}5.6 \text { Humid heat cyclic test } \\
\text { ( } 2 \text { and } 3 \text { acc. To code letter } \mathrm{H} \text { ) }\end{array}$ & $\begin{array}{l}5 \text { cycles, } 25-80{ }^{\circ} \mathrm{C} \\
\max 95 \% \mathrm{rH}\end{array}$ \\
\hline $\begin{array}{l}\text { MST 53-Damp Heat } \\
\text { (DH1000) }\end{array}$ & $85^{\circ} \mathrm{C}, 85 \% \mathrm{rH}, 1000 \mathrm{~h}$ & $\begin{array}{c}\text { 5.7 Damp heat steady state } \\
\text { test }\end{array}$ & $40{ }^{\circ} \mathrm{C}, 85 \% \mathrm{rH}, 500 \mathrm{~h}$ \\
\hline MST 54-UV Preconditioning & $\begin{array}{l}280-320 \mathrm{~nm} / 320-400 \mathrm{~nm}, \\
15 \mathrm{kWh} / \mathrm{m}^{2} \text { or } 60 \mathrm{kWh} / \mathrm{m}^{2}\end{array}$ & 5.9 Solar radiation & $\begin{array}{c}\text { If required, resistance to solar } \\
\text { radiation shall be ensured by } \\
\text { the choice of a suitable } \\
\text { material. }\end{array}$ \\
\hline MST 55-Cold Conditioning & $-40^{\circ} \mathrm{C}, 48 \mathrm{~h}$ & 5.1.1 Low temperature & $-40^{\circ} \mathrm{C}, 24 \mathrm{~h}$ \\
\hline $\begin{array}{l}\text { MST 56-Dry Hot } \\
\text { Conditioning }\end{array}$ & $105^{\circ} \mathrm{C},<50 \% \mathrm{rH}, 200 \mathrm{~h}$ & 5.1.2 High temperature & $85^{\circ} \mathrm{C}, 48 \mathrm{~h}$ \\
\hline
\end{tabular}

Additional climatic stress tests for safety glass components are material dependent and are defined in ECE-R43. There, safety glasses have to pass tests comprising increased temperatures $(\mathrm{A} 3 / 5)$, resistance against radiation $(\mathrm{A} 3 / 6)$, resistance against humidity (A3/7), and resistance against temperature cycling (A3/8) [21]. Polymer materials have to pass a test concerning weatherability (A3/6.4), which comprises UV radiation under damp heat conditions and resistance against humidity (A14/6.4 or A16/6.4) [21]. Disregarding temperature cycling $(\mathrm{A} 3 / 8)$ and increased temperatures $(\mathrm{A} 3 / 5)$, the tests request more stringent requirements compared to IEC 61730-2:2016 and, hence, an additional test sequence is added in the test structure (Figure A1).

\subsection{Chemical Loads}

According to IEC 61730-2, standard PV modules do not have to pass tests concerning their chemical resistance against specific substances. Considering VIPV modules in road traffic, exposition to a variety of chemicals is expected. Within ECE-R43, a test for resistance against chemical substances is described but is recommended to be replaced by referring to ISO 16750-5, because of a greater extent of substances and more stringent pass/fail criteria. 
In ISO 16750-5, a specific collection of chemicals for testing electrical applications mounted on the exterior are defined by referring to code letter $\mathrm{D}$, according to Table 1 [18]. This collection includes urea, cavity protection, protective lacquer, protective lacquer remover, windscreen washer fluid, vehicle washing chemicals, glass cleaner, wheel cleaner, cold cleaning agent, ammonium-containing cleaner, denatured alcohol, and runway deicer. Dependent on the compound, the method applied to the DUT is spraying (I), brushing (II), wiping (III), pouring (IV), dipping (V), and / or immersing (VI), according to Table 2 in ISO 16750-5 [18]. The time span for which the load is applied is also dependent on the chemical compound and lies in the range between $10 \mathrm{~min}$ and $22 \mathrm{~h}$, either at room temperature or at the maximum operating temperature, as defined by the corresponding code letter in ISO 16750-5. Especially during winter, modules will be additionally exposed to salt mist and the resistance of the modules against such high corrosive environments must be ensured as well. Therefore, testing according to IEC 61701 [31] and IEC 60068-2-52 [32] (method 7 and 8 ) is proposed. Since testing mentioned within this section is missing in IEC 61730-2 but is indispensable to ensure the resistance of modules against chemical loads especially in urban environments, the previously mentioned test loads are recommended to be added to the qualification program.

\section{Conclusions}

Here, we demonstrate that, compared to a certification of conventional, planar PV modules, the homologation of VIPV modules poses additional effort. The main reason is that the module safety and, hence, the roadworthiness must be ensured by adherence to several further regulations and standards from the automotive side, before a homologation process by the road authorities can be completed. The already existing extensive safety testing, as defined in IEC 61730:2016 and IEC 61215:2021, can serve as a solid basis for a comprehensive safety qualification program for VIPV modules, which can be complemented by the addition and/or modification of tests concerning chemical resistance, mechanical vibration, shock, and impact. According to IEC 61730:2016, a previous system assessment is necessary in order to specify test parameters, e.g., system voltage for electrical testing. The recommended changes and modifications applied to the test sequences in IEC 61730:2016 are summarised within Table 4.

Table 4. Recommended alignments to the basic testing structure defined in IEC 61730-2:2016.

\begin{tabular}{|c|c|}
\hline Recommended Alignments & Motivation \\
\hline $\begin{array}{l}5 \% \text { power loss allowed during stress tests (acc. To IEC } \\
\qquad 61215: 2021 \text { ) }\end{array}$ & Ensure module quality for market acceptance \\
\hline Addition of vibrational tests from ISO 16750-3 & $\begin{array}{l}\text { Ensure mechanical stability throughout vehicle operation, e.g., } \\
\text { during door slamming or rough road driving }\end{array}$ \\
\hline Chemical testing from ISO $16750-5$ & Ensure module stability against chemical loads \\
\hline $\begin{array}{l}\text { Salt mist corrosion testing acc. to IEC 61701 and IEC 60068-2-52 } \\
\qquad(\text { method } 7+8)\end{array}$ & Ensure environmental stability of modules in winter \\
\hline Separate climatic testing acc. to ECE-R43 & Climatic testing for safety glass \\
\hline $\begin{array}{l}\text { Definition of tests for surface strength/scratch and abrasion } \\
\text { resistance }\end{array}$ & $\begin{array}{l}\text { Important for market acceptance in case of snow removal, } \\
\text { shopping cart collision, branch scratching -> enhancement of } \\
\text { cut susceptibility test (IEC 61730-2, MST 12), also other than } \\
\text { polymer materials shall be tested }\end{array}$ \\
\hline Gravel bombardment test & Ensure module quality for market acceptance \\
\hline Continuative testing after breakage & $\begin{array}{c}\text { Ensure safety of possibly damaged modules during } \\
\text { continuative operation }\end{array}$ \\
\hline Increase in max. T during climatic testing to $95^{\circ} \mathrm{C}$ & $\begin{array}{l}\text { Reproduce realistic operation scenarios, e.g., broken VIPV } \\
\text { module -> possible undetected hot-spot formation }\end{array}$ \\
\hline
\end{tabular}


Modifications in this proposal regarding pass criteria for the functionality of the VIPV modules and adjustments of the testing specifications, e.g., regarding continuative testing of partly broken modules, may have to be addressed in the future. Furthermore, testing of the entire vehicle may pose additional challenges, which were not specifically considered within this investigation.

In Appendix A (Figure A1), our proposal for a qualification program for VIPV modules is finally presented, with the test sequences of IEC 61730-2 [18] as the basic structure. This test scheme was, according to the reasoning presented above, customised to build up a conclusive basic proposal for a VIPV module safety qualification program.

Author Contributions: Conceptualization, J.M., C.K. and M.H.; methodology, J.M. and C.K.; formal analysis, J.M., C.K., P.G., B.N. and M.H.; resources, J.M. and C.K.; data curation, J.M. and C.K.; writing-original draft preparation, J.M. and C.K.; writing-review and editing, J.M., C.K., B.N., P.G. and M.H.; visualization, J.M.; supervision, P.G. and M.H.; project administration, M.H.; funding acquisition, M.H. and C.K. All authors have read and agreed to the published version of the manuscript.

Funding: This research was funded by the German Ministry of Economic Affairs and Energy (FKZ 03EE1002A “Lade-PV").

Institutional Review Board Statement: Not applicable.

Informed Consent Statement: Not applicable.

Data Availability Statement: Not applicable.

Acknowledgments: We would like to thank the Technology Center of DEKRA Automobil GmbH and Menno Hochstenbach from Flanders Make for their guidance into the topic and the fruitful discussions.

Conflicts of Interest: The authors declare no conflict of interest. 


\section{Appendix A}

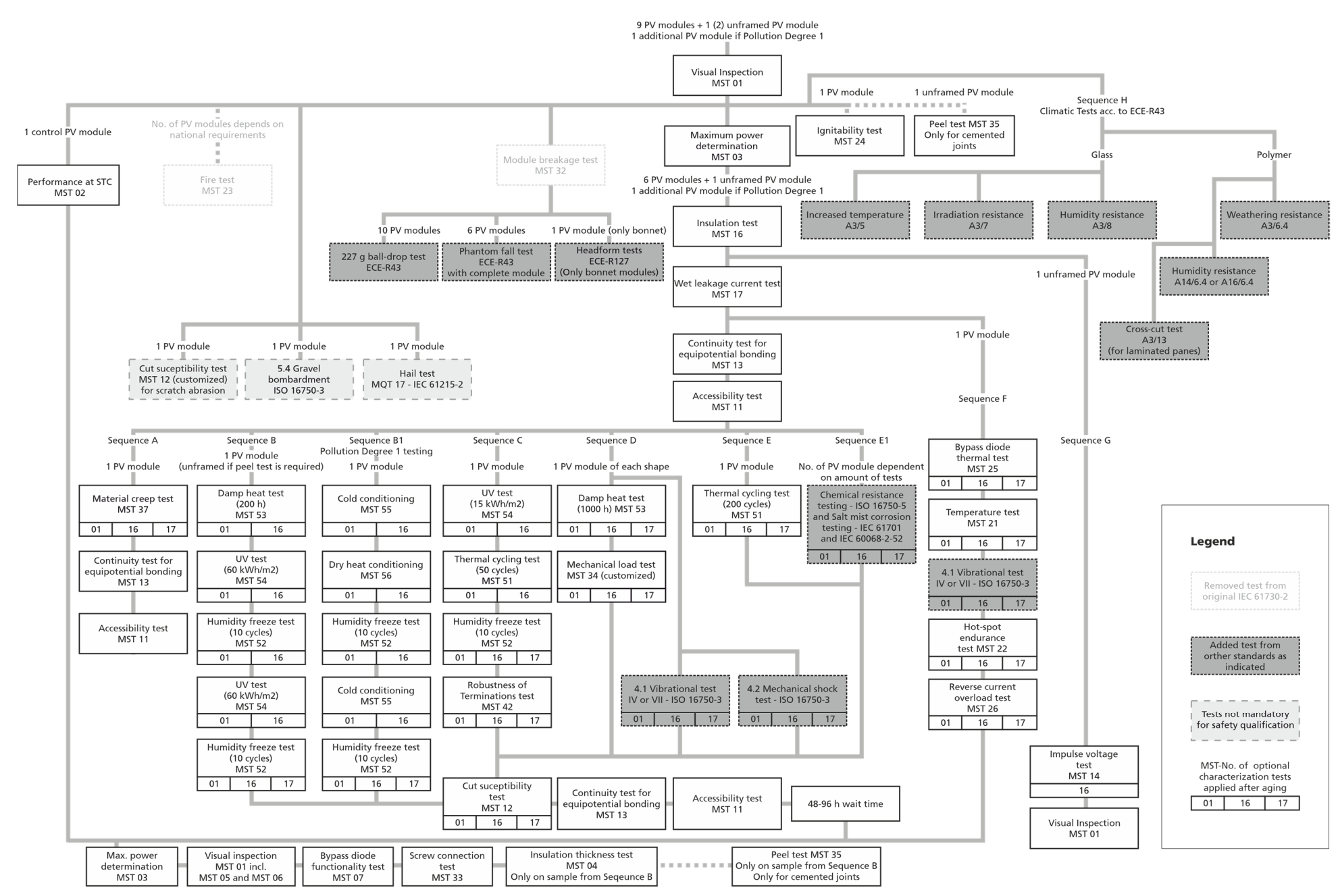

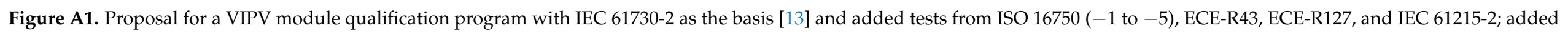
tests, as well as removed ones from the previous existing structure, are indicated; qualification testing is labeled separately. 


\section{References}

1. Kutter, C.; Basler, F.; Neuhaus, D.H.; Heinrich, M.; Markert, J.; Alanis, L.E. Integrated Lightweight, Glass-Free PV Module Technology for Box Bodies of Commercial Trucks. In Proceedings of the 37th European Photovoltaic Solar Energy Conference and Exhibition, WIP Renewable Energies, Lisbon, Portugal, 7-11 September 2020; pp. 1711-1718. [CrossRef]

2. Heinrich, M.; Kutter, C.; Basler, F.; Mittag, M.; Alanis, E.; Eberlein, D.; Schmid, A.; Reise, C.; Kroyer, T.; Neuhaus, H.; et al. Potential and Challenges of Vehicle Integrated Photovoltaics for Passenger Cars. In Proceedings of the 37th European Photovoltaic Solar Energy Conference and Exhibition, WIP Renewable Energies, Lisbon, Portugal, 7-11 September 2020.

3. Carr, A.J.; Burgers, A.R.; van den Tillaart, E.; Kohler, T.; Newman, B.K. Quantifying the benefit of VIPV. Sol. Mobil. Forum Woensdag 16 Sept. 2020, 2020, 1.

4. Carr, A.J.; van den Tillaart, E.; Burgers, A.R.; Köhler, T.; Newman, B.K. Vehicle integrated photovoltaics: Evaluation of the energy yield potential through monitoring and modelling. In Proceedings of the 37th European Photovoltaic Solar Energy Conference and Exhibition, WIP Renewable Energies, Lisbon, Portugal, 7-11 September 2020.

5. Yamaguchi, M.; Masuda, T.; Araki, K.; Sato, D.; Lee, K.-H.; Kojima, N.; Takamoto, T.; Okumura, K.; Satou, A.; Yamada, K.; et al. Development of high-efficiency and low-cost solar cells for PV-powered vehicles application. Prog. Photovolt: Res. Appl. 2020, 29, 684-693. [CrossRef]

6. ITRPV. International Technology Roadmap for Photovoltaic (ITRPV): 2020 Results, April 2021; No. 12, Frankfurt, 2021. Available online: https: / / itrpv.vdma.org/download (accessed on 10 May 2021).

7. Hyundai Motor Company. 2020 SONATA Hybrid-Solar Roof Panel. Available online: https://www.hyundaiusa.com/us/en/ vehicles/sonata-hybrid (accessed on 3 March 2021).

8. Toyota. Prius Plugin. Available online: https://www.toyota.de/automobile/prius-plugin/ (accessed on 3 February 2021).

9. Baliozian, P.; Klasen, N.; Wöhrle, N.; Kutter, C.; Stolzenburg, H.; Münzer, A.; Saint-Cast, P.; Mittag, M.; Lohmüller, E.; Fellmeth, T.; et al. PERC-based shingled solar cells and modules at Fraunhofer ISE. Photovolt. Int. 2019, 43, 129-145.

10. Sono Motors GmbH. Sion. Available online: https:/ / sonomotors.com/de/sion/ (accessed on 3 February 2021).

11. Lightyear. Design-Solar Roof and Hood. Available online: https://lightyear.one/lightyear-one/ (accessed on 3 March 2021).

12. International Electrotechnical Commission. IEC 61730: Photovoltaic (PV) Module Safety Qualification-Part. 1, Edition 2.0; International Electrotechnical Commission: Geneva, Switzerland, 2016; IEC 61730-1.

13. International Electrotechnical Commission. IEC 61730: Photovoltaic (PV) Module Safety Qualification-Part. 2, Edition 2.0; International Electrotechnical Commission: Geneva, Switzerland, 2016; IEC 61730-2.

14. International Electrotechnical Commission. IEC 61215: Terrestrial Photovoltaic (PV) Modules: Design Qualification and Type ApprovalPart. 1: Test. Requirements, Edition 2.0; International Electrotechnical Commission: Geneva, Switzerland, 2021; IEC 61215-1:2021.

15. International Electrotechnical Commission. IEC 61215: Terrestrial Photovoltaic (PV) Modules: Design Qualification and Type ApprovalPart. 2: Test. Procedures, Edition 2.0; International Electrotechnical Commission: Geneva, Switzerland, 2021; IEC 61215-2:2021.

16. Regulation (EC) No 661/2009 of the European Parliament and of the Council of 13 July 2009. In Concerning Type-Approval Requirements for the General Safety of Motor Vehicles, Their Trailers and Systems, Components and Separate Technical Units Intended Therefor; European Parliament and Council: Brussels, Belgium, 2009.

17. Regulation (EU) 2018/858 of the European Parliament and of the Council of 30 May 2018 on the approval and market surveillance of motor vehicles and their trailers, and of systems, components and separate technical units intended for such vehicles, amending Regulations (EC) No 715/2007 and (EC) No 595/2009 and repealing Directive 2007/46/EC. Off. J. Eur. Union 2018, OJ L 151, $1-218$.

18. International Organization for Standardization. ISO 16750 2010-04: Road Vehicles-Environmental Conditions and Testing for Electrical and Electronic Equipment-Part. 1-5, 3rd ed.; ISO: Geneva, Switzerland, 2018.

19. International Organization for Standardization. ISO 20653-Road Vehicles-Degrees of Protection (IP Code)—Protection of Electrical Equipment Against Foreign Objects, Water and Access, 2nd ed.; ISO: Geneva, Switzerland, 2013.

20. Regulation No 10 of the Economic Commission for Europe of the United Nations (UN/ECE) - Uniform Provisions Concerning the Approval of Vehicles with Regard to Electromagnetic Compatibility: UNECE R10; Economic Commission for Europe of the United Nations: Geneva, Switzerland, 2012.

21. Regulation No 43 of the Economic Commission for Europe of the United Nations (UN/ECE)—Uniform Provisions Concerning the Approval of Safety Glazing Materials and Their Installation on Vehicles: UNECE R43; Economic Commission for Europe of the United Nations: Geneva, Switzerland, 2009.

22. Publications Office of the European Union. Regulation No 95 of the Economic Commission for Europe of the United Nations (UNECE)Uniform Provisions Concerning the Approval of Vehicles with Regard to the Protection of the Occupants in the Event of a Lateral Collision [2015/1093]: UNECE R95; Economic Commission for Europe of the United Nations: Geneva, Switzerland, 2014.

23. Regulation No 100 of the Economic Commission for Europe of the United Nations (UNECE)-Uniform Provisions Concerning the Approval of Vehicles with Regard to Specific Requirements for the Electric Power Train [2015/505]: UNECE R100; Economic Commission for Europe of the United Nations: Geneva, Switzerland, 2014.

24. Regulation No 118 of the Economic Commission for Europe of the United Nations (UN/ECE)—Uniform Technical Prescriptions Concerning the Burning Behaviour of Materials used in the Interior Construction of Certain Categories of Motor Vehicles: UNECE R118; Economic Commission for Europe of the United Nations: Geneva, Switzerland, 2005. 
25. Addendum 126: Regulation No. 127-Uniform Provisions Concerning the Approval of Motor Vehicles with Regard to Their Pedestrian Safety Performance; United Nations: Geneva, Switzerland, 2012.

26. Directive 2011/65/EU on the restriction of the use of certain hazardous substances in electrical and electronic equipment. Off. J. Eur. Union 2011, OJ L 174, 88-110.

27. International Electrotechnical Commission. IEC 61140: Protection Against Electric Shock—Common Aspects for Installation and Equipment, Edition 4.0; International Electrotechnical Commission: Geneva, Switzerland, 2016; IEC 61140:2016.

28. International Electrotechnical Commission. IEC 60112: Method for the Determination of the Proof and the Comparative Tracking Indices of Solid Insulating Materials, Edition 5.0; International Electrotechnical Commission: Geneva, Switzerland, 2020; IEC 60112:2020.

29. International Electrotechnical Commission. IEC 60050-212: International Electrotechnical Vocabulary (IEV)—Part. 212: Electrical Insulating Solids, Liquids and Gases, Edition 2.0; International Electrotechnical Commission: Geneva, Switzerland, 2010; IEC 60050-212.

30. International Electrotechnical Commission. IEC 60695-11-10: Fire Hazard Testing-Part. 11-10: Test. Flames-50 W Horizontal and Vertical Flame Test Methods, Edition 2.0; International Electrotechnical Commission: Geneva, Switzerland, 2013; IEC 60695-11-10:2013.

31. International Electrotechnical Commission. IEC 61701: Photovoltaic (PV) Modules—Salt Mist Corrosion Testing, Edition 3.0; International Electrotechnical Commission: Geneva, Switzerland, 2020; IEC 61701:2020.

32. International Electrotechnical Commission. IEC 60068-2-52: Environmental Testing-Part. 2-52: Tests-Test. Kb: Salt Mist, Cyclic (Sodium Chloride Solution), Edition 3.0; International Electrotechnical Commission: Geneva, Switzerland, 2017; IEC 60068-2-52. 